\title{
O SENTIDO DAS CATÁSTROFES NATURAIS NA MÍDIA: DA PREVENÇÃO À ADAPTAÇÃO
}

\section{The Sense of Natural Disasters: From Prevention to Adaptation}

\section{El sentido de los desastres naturales: de la prevención a la adaptación}

Marta de Araújo Pinheiro, Universidade Federal do Rio de Janeiro (Brasil)

martaarpinheiro@gmail.com

Recebido: março 14, 2016

Aprovado: Julho 11, 2016

\section{RESUMO}

O pressuposto deste trabalho repousa sobre a ideia de que os "desastres naturais", em diferentes ocasiões, mobilizam discursos em que as causalidades indicadas moldam um quadro de sentido. Reconhecendo a mídia como vetor ativo da cultura contemporânea, ao analisar uma série de artigos, busca-se acompanhar os traços de esquemas explicativos oferecidos às catástrofes ocorridas com as chuvas nos anos de 1988 e 2011, no Estado do Rio de Janeiro. Conclui-se que há expressiva ausência da problematização da vulnerabilidade social e o predomínio mais recente de medidas de preparação ou de ajustamentos, no sentido de adaptar as populações a "viver com o risco".

Palavras-chave: desastres naturais, discurso de catástrofes, mídia, Brasil.

\section{ABSTRACT}

The assumption of this paper is on the idea that "natural disasters" in different occasions mobilize discourses in which their causalities constitute a sense framework. Recognizing the media as an active vector in contemporary culture, the objective is to analyze a series of articles tracing the explanatory schemes offered to catastrophes due to the 


\section{DISERTACIONES}

floods that occurred in the State of Rio de Janeiro, Brazil, in 1988 and in 2011. The conclusion highlights a significant lack of questioning of social vulnerability, and a newfound predominance of preparedness measures or adjustments in order to adapt the population to "living with risk".

Keywords: Natural disasters, disasters discourse, media, Brazil.

\section{RESUMEN}

La asunción de este trabajo se basa en la idea de que los desastres naturales en diferentes ocasiones movilizan discursos en los que las causalidades constituyen un marco de sentido. Reconociendo los medios como un vector activo en la cultura contemporánea, el objetivo es analizar una serie de artículos trazando los esquemas explicativos que se ofrecen a las catástrofes debido a las inundaciones ocurridas en el Estado de Río de Janeiro, Brasil, en 1988 y 2011. La conclusión resalta la importante falta de cuestionamiento sobre la vulnerabilidad social, y un predominio recién descubierto de medidas de preparación o ajustes con el fin de adaptar a la población a "vivir con el riesgo".

Palabras clave: desastres naturales, discurso sobre desastres, medios, Brasil.

\section{Introdução}

Nas últimas décadas, os desastres ${ }^{1}$ ambientais e climáticos se tornaram um horizonte comum do pensamento em um mundo globalizado (Bourg et al., 2013). A multiplicação dos riscos e a incapacidade de controlá-los, apesar dos diversos dispositivos que têm sido acionados para preveni-los, fazem com que os desastres pareçam inevitáveis;

1 Segundo a definição da Agência das Nações Unidas para Prevenção de Desastres, The United Nations International Strategy for Disaster Reduction (UNISDR), desastre é "uma grave perturbação do funcionamento de uma comunidade ou de uma sociedade envolvendo perdas humanas e impactos materiais, econômicos ou ambientais generalizados que excedem a capacidade da comunidade ou da sociedade afetada de se recuperar com seus próprios recursos". Nossa tradução de: "a serious disruption of the functioning of a community or a society involving widespread human, material, economic or environmental losses and impacts, which exceeds the ability of the affected community or society to cope using its own resources. Disponível em http://www.unisdr.org/files/7817_UNISDRTerminologyEnglish.pdf. Acesso: março de 2014. 
o "viver com risco" (ISDR, 2002), entoado por organizações internacionais, reforça a aceitação de que, a qualquer momento, uma catástrofe de grandes proporções pode ocorrer.

No Brasil, a cada verão, já se aguarda a próxima catástrofe ${ }^{2}$ provocada pelas chuvas e enchentes. As cenas se repetem causando sempre tristeza e busca por respostas e soluções: temporais intensos, desabamentos, mortos, feridos, pessoas que perdem suas casas e lembranças, errantes que procuram seus familiares. 0 "viver com risco" parece ser o nosso cenário habitual.

Apesar desse cenário recorrente, "o viver com risco" está mais presente nas preocupações brasileiras sobre "desastres naturais" . Como indícios dessa atenção, após as enchentes de 2011 ocorridas no Estado do Rio de Janeiro, podem ser citados: a implantação, por parte do Governo Federal, do Centro de Monitoramento e Alertas de Desastres Naturais (Cemaden), que forma um sistema responsável por gerenciar as informações emitidas por radares, pluviômetros e previsões climáticas; a lei n 12.608, de 10 de abril de 2012, que institui a Política Nacional de Proteção e Defesa Civil - PNPDEC; e o crescimento de pesquisas sobre o tema ${ }^{4}$ nas ciências sociais brasileiras.

Os "desastres naturais" aparecem com o caráter de serem imprevisíveis e surpreendentes. Mundialmente, além da busca de ações de antecipação e prevenção (como reflorestamentos, contenção de encostas, melhoria dos serviços meteorológicos, mapeamento de áreas de risco), conta-se com a presença de cenários fictícios, exercícios e simulações do inesperado ${ }^{5}$, nos quais os cidadãos são convidados a habitar o acontecimento catastrófico antes de ele ocorrer. Visa-se tornar as sociedades e as comunidades aptas a responder adequadamente aos eventos, monitorá-los, antecipá-los e a aprender com eles, fortalecendo sua capacidade de reação e adaptação durante e após os desastres.

Verifica-se que ao lado do modelo de "prevenção de desastres naturais", baseado na identificação das vulnerabilidades $^{6}$, outro modelo de "adaptação ao acontecimento catastrófico" passa a coexistir: a imagem da preven-

2 Neste texto, os termos "desastre natural" e "catástrofe" são empregados sem preocupação de se fazer uma distinção conceitual mais apurada. Desastre natural se refere ao acontecimento e catástrofe à sua construção enquanto discurso. Para uma análise mais apurada sobre o conceito de catástrofe, ver Pinheiro (2015).

3 Usa-se a expressão entre aspas porque embora causados por fenômenos naturais, estes desastres são antes sociais e políticos do que só "naturais".

4 Entre outros exemplos, podem ser citados o Centro em Conhecimento em Saúde Pública e Desastres, http://andromeda.ensp.fiocruz.br/desastres/; o Núcleo de Estudos e Pesquisas Sociais em Desastres do Departamento de Sociologia da Universidade Federal de São Carlos, com destaque para os trabalhos de Norma Valêncio, Victor Marchezini, Mariana Siena; na antropologia, Renzo Taddei. No campo da comunicação social, destacam-se as pesquisas de Marcia Franz do Amaral e Paulo Gibaldi Vaz.

5 Pode-se citar como exemplo no Brasil: http://www.brasil.gov.br/defesa-e-seguranca/2012/11/moradoresde-areas-de-risco-de-sete-estados-participam-de-simulados. Acesso: abril de 2015

6 A vulnerabilidade é definida no Marco de Ação de Hyogo como: "Condições determinadas por fatores ou processos físicos, sociais, econômicos e ambientais que aumentam a suscetibilidade de uma comunidade ao impacto de riscos". Nossa tradução de: "Vulnerability is defined in the Hyogo Framework for Action as: "The conditions determined by physical, social, economic and environmental factors or processes, which increase the susceptibility of a community to the impact of hazards". In: Sendai Framework for Disaster Risk Reduction 2015 - 2030. p. 10, nota 4. Disponível em http://www.unisdr.org/files/43291_sendaiframeworkfordrren.pdf. Acesso: março de 2015 
ção, que corresponde a pôr em questão o contexto da catástrofe, compete agora com a imagem da "catástrofe excepcional", como as resultantes das mudanças climáticas, em que mais do que controlar e reduzir seus efeitos busca-se ser flexível e resiliente ${ }^{7}$ às mudanças. Poder-se-ia dizer que exercícios simulados de evacuação dos desastres tornam-se mais predominantes do que os projetos de identificação para compreender os contextos e as raízes das causalidades dos desastres.

Este artigo é parte de uma pesquisa mais ampla intitulada "Risco, catástrofe e resiliência na mídia". Tal pesquisa analisa a mudança no sentido dos "desastres naturais" e os modos de prevenção, a partir da introdução do conceito de resiliência nas ciências sociais e nas políticas internacionais para prevenção e intervenção dos "desastres naturais". Busca-se mapear e analisar o modo como os acontecimentos ligados às catástrofes ambientais são narrados, previstos e imaginados, o que permite estipular características decisivas no mundo contemporâneo dos desastres.

Neste artigo, o foco está em explorar teórica e empiricamente as bases da proposição acima. Sem pretender a exaustão e sabendo sobre a variedade de materiais que dá forma à procura de um significado para uma catástrofe - entre eles relatórios técnicos, discursos institucionais, depoimentos dos habitantes, comemorações, obras artísticas e a própria mídia como um todo -, elege-se o discurso da imprensa como objeto empírico de análise, pois as notícias divulgadas pelos meios de comunicação fazem parte do cotidiano da maioria da sociedade.

A mídia alimenta o discurso da produção das verdades e dos consensos, o imaginário e a representação do contexto em que as pessoas atuam e vivem. Nesse sentido, interroga-se os dispositivos midiáticos como coprodutores de sentidos sociais. Contudo, sabe-se do limite que tal proposta contém por partir de um conhecimento necessariamente parcial e fragmentado, já que a mídia existe em diversidade. Busca-se o jornal impresso ${ }^{8}$ porque, de modo geral, ele oferece mais detalhes e mais dados do que a mídia jornalística audiovisual.

Utiliza-se como orientação da pesquisa a análise do discurso, segundo os estudos de Michel Foucault, destacando que a intenção principal é problematizar (Foucault, 1984), indagar e analisar os discursos, permanecendo no nível do que está dito, e não descobrir quais discursos são verdadeiros ou quais são falsos. Pretende-se tomar

7 A resiliência é definida como: "A habilidade de um sistema, comunidade ou sociedade exposta a riscos de resistir, absorver, adaptar-se e recuperar-se dos efeitos de um perigo de modo eficiente e oportuno através, por exemplo, da preservação e restauração de suas estruturas básicas e funções essenciais". Nossa tradução de: The ability of a system, community or society exposed to hazards to resist, absorb, accommodate to and recover from the effects of a hazard in a timely and efficient manner, including through the preservation and restoration of its essential basic structures and functions. Escritório das Nações Unidas para a Redução de Riscos de Desastres (UNISDR), "Terminologia sobre a Redução de Risco de Desastres do UNISDR-2009”, Genebra, maio de 2009 (http://www.unisdr.org/we/inform/terminology). Acesso: janeiro de 2014.

8 O levantamento mais recente sobre os hábitos de informação dos brasileiros, a "Pesquisa Brasileira de Mídia 2015" (PBM 2015) revela que, embora a televisão seja o meio de comunicação predominante no país, ainda são os jornais impressos os veículos mais confiáveis. Apesar do percentual de $21 \%$ de brasileiros que leem jornais ao menos uma vez por semana, as notícias neles veiculadas espelham a mídia televisiva, já que essa, no Brasil, está ligada aos grandes conglomerados nacionais de mídia controlados por seis famílias, o que contribui para que os conteúdos das mídias tradicionais - imprensa, televisão e rádio - apresentem pouca diversidade entre eles. 
o discurso em sua exterioridade e positividade (Foucault, 1995), no sentido que ele é produzido e como ele produz este mundo, com seus efeitos de verdade. Isso porque os discursos são "práticas que formam sistematicamente os objetos de que falam" (p. 56).

As análises iniciais das matérias coletadas permitem compreender que as enunciações em evidência nos jornais dão visibilidade às enunciações que são repetidas constantemente de diferentes formas, convidando a sociedade a ver e a falar sobre a problemática dos "desastres naturais". Investigar os vários estágios da vida pública de tais questões requereria a análise dos discursos midiáticos num período de tempo longo, o que obviamente significaria uma quantidade extensa de material analisado. Nesse sentido, o corpus deste artigo restringese às matérias e aos artigos de jornais selecionados em dois momentos históricos distintos. A análise comparativa privilegia a historicidade das operações que tecem as causas, as responsabilidades, as formas de narrar os "desastres naturais", o que permite destacar as concepções singulares e as eventuais transformações discursivas nesses dois diferentes momentos.

O pressuposto deste trabalho repousa sobre a ideia de que os "desastres naturais" em diferentes ocasiões mobilizam discursos em que as causalidades indicadas moldam um quadro de sentido. Os meios de comunicação, ao narrarem uma catástrofe, não apenas a descrevem ,mas também expõem as condições em que ela poderia não ter ocorrido, oferecendo assim um esquema explicativo. Entretanto, não se busca verificar se a representação da catástrofe pela imprensa gera uma resposta adequada ou não entre os leitores, no sentido de sensibilização ao medo, ao sofrimento, ou a sua capacidade de mobilização para uma ação em particular, ou o seu aspecto normativo.

Positivamente, reconhecendo a mídia como vetor ativo da cultura contemporânea, ao analisar uma série de artigos, busca-se acompanhar os traços de esquemas explicativos oferecidos às "catástrofes naturais" em alguns jornais brasileiros. A estratégia metodológica foi desenvolvida diante das seguintes questões: se os desastres causados pelas chuvas são "uma ocorrência natural e sempre esperada", como no Estado do Rio de Janeiro", o que muda na explicação de sua ocorrência? Se cada registro explicativo implica um modo de agir diante das catástrofes, o que muda nos modelos de ação propostos? Para respondê-las, foram formuladas quatro perguntas que guiaram a seleção e a análise do corpo empírico dos jornais pesquisados: qual a causa atribuída à catástrofe? Quais as soluções propostas? Quais as características dessas soluções numa escala entre a mitigação e a transformação? Quais as previsões em relação ao futuro?

A pesquisa empírica teve como objeto as catástrofes provocadas pelas chuvas no Estado do Rio de Janeiro, nos anos de 1988 e 2011. Uma atenção particular foi dada ao primeiro mês das notícias veiculadas nos jornais mais expressivos naqueles anos em termos de tiragem e público: Jornal do Brasil (JB), O Globo e Folha de São Paulo (FSP) (1988) e O Globo e Folha de São Paulo (2011).

As chuvas de fevereiro de 1988 foram escolhidas por serem classificadas como umas das maiores ocorridas no Estado, fazendo rememorar as chuvas de janeiro de 1966, um grande marco na memória dos seus habitantes (Maia e Sedrez, 2011). Já as chuvas de janeiro de 2011 foram selecionadas porque são nomeadas como "a tragé-

9 Percentual dos desastres naturais mais recorrentes no Estado do Rio de Janeiro, no período de 1991 a 2012: movimentos de massa (21\%), inundações (26\%), enxurradas (35\%) e outros (18\%). Fonte: Atlas (2013), p. 17. 
dia" devido ao seu grande impacto e ao seu ineditismo, muitas vezes associados às mudanças climáticas. Para este artigo foram selecionadas, segundo os critérios acima indicados, aquelas matérias que evocavam registros explicativos e propostas de prevenção.

O artigo está estruturado da seguinte forma: inicialmente, justifica-se a importância dos estudos das catástrofes na mídia; a seguir, apresenta-se uma visão geral e resumida dos estudos dos "desastres naturais" na tentativa de expor a transição dos modelos de prevenção e de adaptação para, posteriormente, buscar identificar através das notícias selecionadas os modelos explicativos nos dois momentos analisados.

\section{Os desastres naturais e a mídia}

Em torno dos desastres, legitimados pela ameaça, muitos dispositivos (socorro, assistência, deslocamentos) são ativados em nome de "uma temporalidade de urgência". Acima de tudo, desastres, catástrofes e conflitos estão enredados na mesma lógica de intervenção da urgência justificada tanto por registros morais quanto políticos. Craig Calhoun (2013, p. 30) avalia que "urgência" é hoje o termo primeiro quando se refere às catástrofes. A urgência indica que o acontecimento catastrófico não possui qualquer referência a um agente ou a uma causalidade externa. A cada catástrofe, o atributo de "urgência" qualifica os acontecimentos como repentinos e imprevisíveis, causando sofrimentos e situações perigosas que demandam uma resposta imediata.

O tratamento na mídia também reforça esses acontecimentos como uma "temporalidade da urgência": descontextualizados, eles se movem em torno de uma natureza universal do sofrimento, conferindo uma ordem própria aos desastres, que se torna apolítica e a-histórica, e a cada desastre, parece que as mesmas imagens e os mesmos textos se repetem. Ao lado dessa generalização, o discurso na mídia também visa dar ao "desastre natural" toda sua excepcionalidade, fazendo uso de avaliações às vezes desmesuradas e emocionais, como a contagem de mortos que cresce hora a hora, os sobreviventes que lamentam suas perdas ou que narram suas estratégias pessoais de sobrevivência, os desaparecidos, a agonia dos socorros, as histórias dos mortos, os feridos nos hospitais, a alegria dos reencontros.

A imaginação se abre à incerteza, ao mesmo tempo em que são justapostas explicações que buscam dar sentido a essa desmesura: gráficos, mapas, avaliações de especialistas, rememoração de outras tragédias, identificação de possíveis culpados, planos estratégicos futuros.

Essa construção é um dispositivo para dar um sentido, pois, mesmo que como experiências únicas, os desastres em geral, devido ao seu vazio de significado original, atraem lógicas capazes de transformá-los em fatos esperados. Pode-se dizer que as catástrofes são o resultado de uma interpretação e de um discurso, à medida que ocorre uma construção com base em representações, fotos, depoimentos, análises.

A midiatização de desastres em seu sentido mais amplo (tratamento, representação, impacto), ao mesmo tempo em que marca o caráter excepcional dos fenômenos naturais e das perturbações que causam na vida social normal, busca suprir a falta de sentido sobre o que ocorreu, associando duas mensagens: a descrição, tanto dos fenômenos quanto da dor das vítimas e da angústia dos resgates, e a indicação de uma causalidade que dê sentido àquela urgência.

Por que isso aconteceu? Quem é o culpado? O que vai acontecer? O que deve ser feito agora? O cenário resultante das tentativas de respostas a essas questões entre outras é uma forma de escrita da realidade que busca

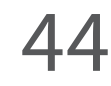


colocar este "evento crítico" como forma discursiva, narrativa e, sobretudo, normativa de explicação do desastre. Para entender o "evento crítico" para além de sua urgência, em sua perspectiva social e política maior, é necessário registrá-lo novamente em uma perspectiva mais longa, a fim de lhe dar maior densidade e não tratá-lo como "puro evento" (Revet, 2007).

Em relação à "temporalidade da urgência da mídia", uma estratégia é inseri-la em um "tempo longo", comparando notícias sobre "desastres naturais" em momentos afastados, restituindo às catástrofes seu caráter de construção de modo a extrair as suas diferenças e os seus traços comuns. Considerando que uma catástrofe não é reduzível a um acontecimento localizado e datado (e menos ainda ao fato de um conjunto de fenômenos empíricos que seria totalmente desconectado de uma interpretação), considera-se a catástrofe como uma construção social elaborada por diferentes públicos e segundo temporalidades que se superpõem e detém uma parte ficcional significante (Revet, 2007). E nesse sentido, justifica-se estudar o discurso da mídia para além da sua "temporalidade de urgência".

\section{As ciências sociais e os desastres}

As catástrofes enquanto acontecimento têm sido objeto de estudo das ciências sociais há várias décadas. Já no século XVIII, com a "laicização dos desastres", o estudo dos terremotos, erupções vulcânicas e enchentes passa pela compreensão dos especialistas em ciências naturais que visavam seu controle através do progresso técnico e científico, calculando a probabilidade de ocorrência dos fenômenos naturais, como modo de proteger a sociedade. Neste momento, "o perigo natural"10 designa um acontecimento que tem como origem um fenômeno natural e não provocado pela ação humana.

Nos anos 1950, no contexto da Guerra Fria, nos Estados Unidos, é criado o Disasters Studies, que visava compreender e antecipar os comportamentos da população em uma situação de desastre, no caso de um ataque nuclear, por exemplo. Ainda nesse país, na década de 1960, nascido da observação da incapacidade das abordagens apenas científicas e técnicas, surge o Disaster Research Center (Quarantelli, 2002), que inclui uma abordagem sociológica e psicológica sobre o comportamento da população diante dos desastres, mas considerando ainda, naquele momento, suas causas - ameaças naturais incontroláveis - como sendo exteriores à sociedade atingida (Collier et Lakoff, 2008).

Nos anos 1970/80, pesquisadores da geografia humana buscam tratar os desastres naturais não mais como exteriores à sociedade, mas colocando-os sob uma perspectiva econômica, social e política: as catástrofes não são uma ruptura da ordem normal das coisas, mas sim o produto desta ordem (Hewitt, 1983). A vulnerabilidade congrega nas abordagens que, a partir da década de 1980, refutam a ideia de que as principais causas da fome, por exemplo, são a ausência de chuva e a irracionalidade das práticas tradicionais. Ao contrário, a fome e as catástrofes são reveladoras de uma situação de dominação anterior que resulta na maior vulnerabilidade de certas sociedades aos "desastres naturais": história colonial, destruição de saberes e práticas tradicionais, desenvolvimento desordenado.

10 Perigo (hazard): condição ou fenômeno com potencial para causar uma consequência desagradável (Ministério das Cidades/IPT, 2007). 
Na América Latina, nos anos 1990, um grupo de pesquisadores chamado La RED (La Red de Estudios Sociales en Prevención de Desastres en América Latina), compartilha a percepção das catástrofes como não sendo exteriores à sociedade. Essa rede foi criada a partir da ideia de que os desastres não são naturais e sim o resultado de condições socioeconômicas vulneráveis, sendo a vulnerabilidade uma construção social: são os aspectos físicos e materiais, as dimensões sociais, tais como a fragilidade da unidade familiar, o acesso à propriedade ou ao crédito, a discriminação social ou política, a ausência de educação. Os pesquisadores se esforçam para promover uma abordagem dos "desastres naturais" que leve em conta fatores de "vulnerabilidade social", isto é, o reconhecimento dos contextos locais e dos grandes problemas estruturais de desenvolvimento.

Essas obras tiveram certa influência para reorientar as políticas internacionais para a prevenção de catástrofes durante a década de 1990, integrando a noção de vulnerabilidade social e a ideia de que os desastres podem ser prevenidos com ações sobre o contexto social e o nível de desenvolvimento dos países (Revet, 2011). Essas pesquisas se desenvolveram nos países latino-americanos e no chamado Terceiro Mundo, e compreendem os desastres naturais como processos e construções culturais, reforçando assim os fatores estruturais e históricos que estariam nas bases das catástrofes, repolitizando as catástrofes naturais, afirmando que "os desastres não são naturais" (Maskrey, 1993). Esses pesquisadores defendem práticas políticas na prevenção e atenção, não só às grandes catástrofes ,mas também às pequenas, a todos os eventos micro, pois afirmam que os efeitos cumulativos são mais importantes do que as "grandes catástrofes midiatizadas".

Contudo, nesse mesmo período, a noção de vulnerabilidade não está isenta de críticas nos estudos de alguns pesquisadores. Entre eles, Greg Bankoff (2003) propõe ser esta uma categoria que confina as pessoas ou as sociedades como vítimas passivas e frágeis, sendo mais uma das representações ocidentais dos males que assolam os países mais pobres ao identificar certas partes do mundo como "sem segurança". Ele identifica e critica as soluções propostas pelos países ocidentais e agências internacionais: diante da doença, a medicina; diante da pobreza, o desenvolvimento; diante do risco, a ciência ou a tecnologia.

O desenvolvimento da pesquisa que associa a vulnerabilidade ao estudo das catástrofes avança durante a Década Internacional de Prevenção das Catástrofes Naturais (International Decade for Natural Disaster Reduction - IDNDR), criada em 1990 pelas Nações Unidas. Becerra e Peltier (2011) acentuam dois aspectos que marcam as novas pesquisas sobre "desastres naturais": 1. O poder da ciência e da tecnologia para a redução dos desastres; 2. A importância da educação das pessoas. Salvar vidas é objeto de consenso e os meios para isso não estão em questão. Segundo as autoras, surgem neste contexto modelos para responder à pergunta: como ocorrem catástrofes? Com base na equação clássica "risco = perigo x vulnerabilidades", os modelos oferecem uma análise das catástrofes como resultado da ocorrência de um perigo cujo impacto é agravado por vários processos de vulnerabilidade, fazendo a distinção entre o que provoca (causas), a vulnerabilidade (acesso limitado aos recursos do governo, as ideologias) e as pressões (mercado, instituições, treinamento, etc.), que influenciam essas vulnerabilidades "originais" e inseguranças ambientais, econômicas ou sociopolíticas.

Apesar da tendência a aproximar o entendimento das catástrofes a modelos que buscam incluir cada vez mais esses fatores, Gilbert (2009) observa que a imprevisibilidade da catástrofe torna-se uma desculpa "conveniente" para as autoridades. Para muitos governos e instituições internacionais, a mudança climática atual é um álibi fácil que lhes permite fugir de sua responsabilidade na "vulnerabilização" do planeta. O aumento do número de catástrofes, na verdade, está relacionado a uma causalidade complexa que inclui a demografia, o histórico-cultural e os 
constrangimentos político-econômicos que se entrelaçam. Gilbert propõe ir além da definição de vulnerabilidade social (como todos os danos ou perdas humanas após um desastre), tendo em conta as capacidades das comunidades para evadir ou resistir aos efeitos de fenômenos naturais através das ações e políticas comuns.

Também se difunde nos anos 1990 (cruzando os temas da mudança climática e da adaptação) a temática da resiliência como a capacidade de enfrentar ou se adaptar, tanto a uma catástrofe quanto a uma situação de crise ou de estresse. Ela inclui tanto medidas de preparação ou de ajustamentos em todos os níveis, quanto designa resistir à mudança induzida por uma catástrofe a fim de reencontrar um nível aceitável de funcionamento. Mais do que tentar controlar ou reduzir os efeitos, deve-se adaptar às mudanças adquirindo capacidades para se atingir certa flexibilidade, criando cenários fictícios e simulações do inesperado, em que a imaginação e a experiência sensorial têm um papel crescente na antecipação de habitar futuros desconhecidos (Aradau, 2014). Tal abordagem se opõe à discussão de tendências e dos modelos de prevenção construídos através do conhecimento dos modos de desenvolvimento de cada sociedade e de suas complexidades locais, em que a tecnologia não é a única base para a prevenção, dada a importância das populações locais nas políticas de redução do risco.

Críticos ao modelo da resiliência acreditam que simulações e mapeamentos de vulnerabilidade engendram o medo e a ansiedade diante da constatação de que "não se está preparado", o que leva os praticantes a melhorar constantemente sua prontidão (Lakoff, 2007). Esse medo da vulnerabilidade constante é "construído" na população civil através de programas de treinamento e educação. Como tal, técnicas de preparação podem transformar catástrofes imprevisíveis em vulnerabilidades que podem ser atenuadas por modificações comportamentais (Grove: 2014), e ao enfatizar salvar a vida de "vítimas" em momentos de coação, não se procura mais intervir nas condições de vida dos seres humanos como membros de uma coletividade social (Lakoff, 2007, p. 27).

É nesse quadro de questões que se acredita na importância da comunicação, não só em sua atuação direta, como na "comunicação de risco", como também na compreensão da mídia como uma mediadora desses modelos na conceituação e nas ações relativas à prevenção das catástrofes.

\section{Desastres naturais: as chuvas no Estado do Rio de Janeiro}

O Estado do Rio de Janeiro situado na região sudeste do Brasil possui 15.999.929 habitantes, de acordo com os resultados do Censo Demográfico de 2010 (IBGE), e está situado numa estreita faixa de terra ao longo do litoral brasileiro. Em seu interior, existe uma grande cadeia de montanhas, a Serra da Mantiqueira, e a vegetação típica do Estado é a floresta tropical, chamada de Mata Atlântica, cuja maior parte foi dizimada pela ação do homem para dar lugar a plantações, pastos e cidades.

Na época do verão, devido ao clima tropical, ocorrem chuvas abundantes, geralmente causando enchentes e desmoronamentos. A cidade do Rio de Janeiro é a capital do Estado, a segunda maior cidade do país e a terceira maior região metropolitana da América do Sul.

O processo de urbanização no Brasil, durante a segunda metade do século XX, ocorreu de modo acelerado, concentrado e, principalmente, ao longo da costa brasileira e nas principais capitais. A urbanização não foi resultado de um processo planejado que respondesse às necessidades de uma maior densidade demográfica. 0 reflexo disso foi a consolidação de regiões densamente povoadas em zonas sem infraestrutura e urbanização, frágeis 
ecologicamente e habitada por pessoas que possuem menor poder socioeconômico, como nas favelas ou nos "aglomerados subnormais", conforme denominação adotada oficialmente pelo IBGE a partir do Censo de $2010^{11}$.

Os "desastres naturais" que ocorrem nas cidades brasileiras não podem ser só atribuídos aos fenômenos naturais ou simplesmente à ocupação de zonas inapropriadas do ponto de vista geotécnico. Eles são também resultados de que o espaço urbano é um lugar onde as desigualdades sociais são mais visíveis: os locais com melhores condições geotécnicas e urbanas são os mais caros, enquanto os com piores condições são ocupados pelos mais pobres. É importante observar que em muitas cidades, como na cidade do Rio de Janeiro e em outras da Região Serrana desse Estado, os locais com melhores e piores condições de urbanização convivem lado a lado.

\section{As chuvas de fevereiro de 1988}

Nesse ano, um temporal de trinta minutos provocou deslizamentos, desabamentos, casas e pessoas levadas pelas águas, deixando inúmeros desabrigados e 134 mortos só na cidade do Rio de Janeiro, sendo que 40 eram idosos de uma clínica que desmoronou, no bairro de Santa Tereza. Em Petrópolis ${ }^{12}, 170$ pessoas morreram em desabamentos e 600 ficaram desabrigadas. Em resumo, as enchentes e os deslizamentos no Estado do Rio de Janeiro terminaram com 289 mortos, 734 feridos e 18.560 desabrigados na Baixada Fluminense ${ }^{13}$ e na Região Serrana ${ }^{14}$.

Com as chuvas anteriores nos anos de 1966 e 1967, o Estado do Rio de Janeiro foi palco de uma grande polêmica sobre a erradicação ou urbanização das favelas. Elas eram consideradas locais que ofereciam riscos de segurança e de vida durante as chuvas, tanto para seus próprios moradores quanto para a "população do asfalto" próxima aos morros ocupados pelas favelas. Para o historiador Rafael S. Gonçalves (2015), as chuvas de 1988 suscitaram um questionamento da política anterior de urbanização das favelas e consolidaram a maior segurança jurídica dos moradores com o fim das remoções, em que: "as consequências políticas diretas das chuvas foram,

11 De acordo com Censo de 2010, cerca de 11,4 milhões de pessoas (6\% da população) vivem em aglomerados subnormais. "Aglomerados subnormais", nomenclatura adotada pelo Censo 2010, engloba os diversos tipos de assentamentos irregulares existentes no país (como favelas, invasões, grotas, baixadas, comunidades, vilas, ressacas, mocambos, palafitas, entre outros), isto é, áreas do país com ocupação irregular com, no mínimo, 51 unidades habitacionais consideradas carentes, com falta de serviços públicos e de urbanização. O Rio de Janeiro é a cidade com maior número de pessoas morando em favelas, com 1.393.314 habitantes (22\% da população total). Disponível em http://www.ibge.gov.br. Acesso: janeiro de 2015.

12 Petrópolis é um município localizado no interior do estado do Rio de Janeiro. Ocupa uma área de 795,798 $\mathrm{km}^{2}$, contando com uma população de 295.917 habitantes (2010), segundo o IBGE. Em 2013, o PIB per capita é de 31.753,67 reais. Disponível em http://cidades.ibge.gov.br. Acesso: abril de 2015.

13 Baixada Fluminense é o nome que se dá à região em redor do município do Rio de Janeiro. Mais de 3 milhões de habitantes vivem na área, a segunda mais populosa do estado, que só perde para a capital, a cidade do Rio de Janeiro.

14 A Região Serrana possui 16 municípios, com uma população de 490.311 habitantes (IBGE, 2010), representando 5,3\% da população total do estado. A região é composta pelos seguintes municípios: Bom Jardim, Cachoeira de Macacu, Cantagalo, Carmo, Cordeiro, Duas Barras, Guapimirim, Macuco, Nova Friburgo, Petrópolis, Santa Maria Madalena, São José do Rio Preto, São Sebastião do Alto, Sumidouro, Teresópolis e Trajano de Moraes. 
de um lado, a ampliação do programa de contenção de encostas e eliminação de riscos (...) e, de outro lado, o estímulo ao prosseguimento do projeto Reflorestamento Comunitário" (Gonçalves, 2015, p.114).

Ao analisar os textos jornalísticos publicados no ano de 1988, um elemento que se destaca nas coberturas são os depoimentos de especialistas que reforçam o fator humano como coautor dos desastres naturais: "[...] a presença do homem torna um fato natural em catástrofe [...] como a ocupação dos morros [...]" (FSP, 29/02, p. A13). Mas essa relação é percebida como uma guerra entre a natureza e os governantes: "o Rio de Janeiro conheceu o seu definitivo Waterloo diante da conjugação de forças da natureza e da irresponsabilidade de sucessivos governos" (JB, 21/12, p. 10). A responsabilidade recai sobre a falta de uma política de planejamento urbano, pois "o alto índice pluviométrico aliado ao problema social, que faz com que as pessoas construam as suas casas em locais irregulares e perigosos" (JB, 23/02, p. 4). A vulnerabilidade às chuvas é resultado dessa falta de "governo" em planos pontuais diante de um agente duplamente classificado, pois a associação entre favelas e destruição do meio ambiente é a causalidade frequentemente indicada.

Destacam-se aqui dois artigos que resumem o tom das reportagens analisadas. No primeiro, intitulado "Na tragédia de 22 anos atrás, as cenas iguais às registradas ontem", a matéria, ao comparar as chuvas de 1988 àquelas ocorridas em 1966/67, culpabiliza as instâncias públicas pela manutenção de um estado permanente de falta de intervenção, desnaturalizando o desastre. Ao mesmo tempo, em que enumera as mazelas causadas pelos descuidos do Governo que acometem os cidadãos nos momentos de grandes temporais, como canalizações subterrâneas, margens dos rios transformadas em lixeira, falta de urbanização, desmatamento, ausência de bueiros, etc., faz desse estado de vulnerabilidade de seus cidadãos, algo que poderia não existir, caso se submetesse a cidade a uma política de intervenção constante no espaço público.

Relativo às soluções futuras, o segundo artigo é sobre o estudo do Fundo Rio, órgão da Secretaria de Desenvolvimento Econômico e Social, que resume muitas das propostas encontradas, as que utilizam de um argumento econômico para demonstrar que sairia mais barato do que os gastos habituais de emergência e reconstrução: "urbanizar as 480 favelas e os 486 loteamentos irregulares do município, e também os trabalhos de contenção de encostas, dragagens de rios e canais, coleta de lixos e obras de saneamento básico" (JB, 23/02, Cidade, p. 4).

Os pontos comuns percebidos nas matérias dos jornais analisados são os fenômenos naturais, no caso a chuva, transformados em grande catástrofe pela falta de uma política de prevenção e de cuidado com a cidade. $\mathrm{E}$ caso houvesse um governo mais comprometido, a cidade e seus habitantes seriam menos vulneráveis aos danos de uma grande enchente. A vulnerabilidade da cidade e de sua população devido à má gestão política ou à falta de verbas para viabilização de projetos foi a principal razão das ocupações irregulares, com mais destaque às favelas e à destruição do meio ambiente.

Apesar de várias matérias apresentarem a discussão do planejamento da cidade e as disputas políticas entre os projetos de remoção ou de urbanização das favelas, as condições assinaladas de vulnerabilidade, para além da questão da ausência ou da presença pontual de planejamentos urbanos ou decisões políticas emergenciais, não se fazem presentes numa perspectiva de busca de antecedentes, dados históricos, conflitos existentes, escuta de agentes e atores sociais diferentes. Enfim, a vulnerabilidade, entendida em seu sentido mais amplo como vulnerabilidade social histórica atrelada à vulnerabilidade ambiental, não foi observada.

Em resumo, nas matérias encontradas, a vulnerabilidade aos "desastres naturais" é resultado de mau gerenciamento dos governos anteriores, da destruição do meio ambiente pelas ocupações irregulares e pelas favelas 
e da ausência de recursos provenientes dos governos. Como soluções futuras, são propostas ações emergenciais, projetos a longo prazo de infraestrutura e demandas de planejamentos urbanos mais eficientes, sem deixar espaço para uma discussão sobre a "vulnerabilidade social", no sentido de propor abordagens sobre os contextos locais e os problemas de desenvolvimento a longo prazo.

Como expressivo dessa concepção, o editorial "Crimes e covardia contra os humildes" é significativo, dada a inversão da proposição do título ao utilizar o seguinte argumento: os temporais afetam a cidade por problemas de mau gerenciamento, engenharia e limpeza urbana. Já nos morros, aluviões causam muitas mortes apesar das obras de intervenção já feitas, o que significa que lá o gerenciamento eficiente já ocorreu e mesmo assim os desastres continuam a ocorrer. Portanto, o que será colocado com mais virulência é a questão política resumida como demagogia, a impossibilidade da urbanização dos morros e a transferência de sua população, "os humildes" do título:

Os TEMPORAIS atingem o Rio de Janeiro de duas maneiras: em áreas planas, há a enchente de ruas, provocada pelo entupimento de bueiros. O problema é de engenharia e de limpeza de bueiros. Perturba terrivelmente a vida da cidade, mas raramente mata. Ele é causado em muitos bairros pelo descomunal volume de lixo e destroços que desce das favelas situadas nos morros. Nos morros, a situação é muito diferente. As encostas são atingidas por aluviões que espalham a morte por onde passam. Em diversos pontos, obras de contenção são necessárias. Muitas foram realizadas depois das chuvas e a de 1966 e 67 pelo Governo Negrão de Lima, 20 anos depois, é evidente que novo esforço de grandes proporções se faz outra vez necessário. Não está aí, entretanto, o grande problema. Na verdade, o Rio tem sido vítima de covardia e de demagogia de Governos que temem o preço político a ser pago por uma atitude corajosa face à proliferação de favelas nos morros, com a ocupação irracional do solo [...]. É urgente um plano sério de construção de casas populares, como parte de uma política habitacional que reconheça a impossibilidade de urbanização das favelas situadas nos morros [...]. (O Globo, 23-01, capa).

\section{As chuvas de janeiro de 2011}

O desastre da Região Serrana do Estado do Rio de Janeiro ocorreu entre os dias 11 e 12 de Janeiro de 2011. As chuvas intensas provocaram enchentes, devido ao transbordamento de rios e córregos, causando deslizamentos de terra em sete cidades da região serrana, principalmente nas cidades de Nova Friburgo ${ }^{15}$, Teresópolis ${ }^{16}$ e Petrópolis, causando a morte de 947 pessoas. $O$ desastre foi deflagrado por condições climáticas extremas de precipitação e foi considerado um dos maiores eventos de movimentos de massa, decorrentes da geomorfologia da região aliada a uma grande ocupação urbana (Atlas, 2013). Esse acontecimento renovou a importância da prevenção, mitigação

15 Nova Friburgo é um município da Região Serrana do Estado do Rio de Janeiro. Compreende os distritos de Riograndina, Campo do Coelho, Amparo, Lumiar, Conselheiro Paulino, São Pedro da Serra e Mury. De acordo com o Censo (2010), sua população foi estimada em 182.082 habitantes.

16 Teresópolis é um município da Região Serrana, localizado ao norte da capital do estado. Sua população foi estimada em 163.746 habitantes (Censo, 2010). 
e criação de cidades mais resilientes para que suportem melhor as adversidades naturais e diminuam as vulnerabilidades às quais a população está exposta.

As chuvas foram identificadas como "a tragédia" (FSP, O Globo), a maior catástrofe natural (O Globo, 14/01, p. 4), "A dor que une ricos e pobres" (O Globo, 13/01, capa). Apesar de a amplitude da catástrofe ter atingindo residências da classe média e alta da região, não se pode dizer que ela foi igual para todos, pois o número de mortos, desaparecidos, desabrigados e casas destruídas foi imensamente maior na população mais pobre. A partir de dados do Banco Mundial (2012, p. 24-28), constata-se que 91\% dos danos diretos foram concentrados em áreas ocupadas por populações de baixa renda.

Estes títulos, entretanto, são sugestivos sobre a mudança no tratamento das chuvas de 2011 quanto às questões de vulnerabilidade já que, segundo o material analisado, as chuvas atingiram e uniram todos diante da imprevisibilidade das transformações dos eventos "naturais". As populações pobres, que vivem em regiões sem urbanização, passam a concorrer com uma abordagem que privilegia mais os modelos de prevenção voltados a mapeamentos de áreas de risco, de gerenciamento e de treinamento das comunidades, a partir do momento em que os eventos extremos teriam atingido a todos de forma igual, ricos e pobres. Caberia, portanto, indiferentemente das condições sociais, aos moradores de área de risco suportar melhor as adversidades naturais, adaptar suas vulnerabilidades específicas às mudanças e diminuir as vulnerabilidades externas a que estão expostos.

A recorrência a desastres anteriores destaca esta ser a maior tragédia em uma história de muitas repetições, em que tudo continua a mesma coisa e que nada muda: "A história que se repete todos os anos, apenas o cenário muda”(O Globo, 13/01, p.1); "Enquanto isso, no Morro do Bumba ${ }^{17}$, em Niterói, 800 ainda estão na fila para receber aluguel social” (O Globo, 15/01, capa); "Família vê tragédia que se repete nove anos depois” (FSP, 19/01, C4).

Entretanto, o acionamento da memória das outras tragédias não se caracteriza como uma busca por antecedentes que evidenciariam a fragilidade da região geográfica às intempéries, e sim como uma prova da "incompetência" dos governos. O que diferencia essa catástrofe das demais é um argumento de ordem quantitativa, a do número de mortos, que faz com que essas chuvas se tornem "a tragédia": "A quantidade de vítimas supera a de outras tragédias emblemáticas da história do Rio provocadas por enchentes e deslizamentos, como as de 1966 (acima de 200 mortos), 1967 (200 óbitos), 1988 (277 mortos), 2010 (316)" (O Globo, 14/01, p. 4).

Culpados pela catástrofe são nomeados: "Dilma ${ }^{18}$ e Cabral ${ }^{19}$ culpam a ocupação irregular pelo desastre" (FSP, 14-01, p. C1). Especialistas também apontam a ocupação irregular e estendem a responsabilidade às autoridades pela omissão: "No Brasil, houve um absoluto desleixo em relação à população de baixa-renda" (FSP, 14/01, C1). A ocupação irregular, o desleixo das autoridades, a urbanização caótica e o mau uso dos recursos públicos são as causas recorrentes: a "região serrana tinha 42 mil e não 6 mil em áreas de risco" (FSP, 26/01, capa). Moradores em

17 Catástrofe ocorrida em 2010, na favela Morro do Bumba, em Niterói, município do Estado do Rio de Janeiro, quando num deslizamento de terra, 267 pessoas morreram e muitos ficaram desabrigados.

18 Presidente do Brasil, pertencente ao Partido dos Trabalhadores, eleita em $1^{\circ}$ de janeiro de 2011 e reeleita para um segundo mandato nas eleições de 2014.

19 Sérgio Cabral Filho, filiado ao Partido do Movimento Democrático Brasileiro (PMDB), foi governador do Estado do Rio de Janeiro de 1 de Janeiro de 2007 até 3 de abril de 2014, quando renunciou ao cargo. 
áreas de risco, urbanização sem planejamento, má administração pública, os mesmos responsáveis pelas calamidades de 1988.

Entretanto uma nova observação é introduzida em relação ao panorama de 1988. De ordem mais qualitativa, ela também contribui para que essas chuvas sejam denominadas "a tragédia" e servirá como prognóstico para ações futuras: a intensidade inesperada das chuvas e a capacidade de destruição nunca antes observada. A causalidade atribuída é a mudança climática: "pesquisadores dizem que embora seja precipitado associar as chuvas ao aquecimento global, o que aconteceu se encaixa no que dizem os modelos. Isto é, as chuvas ficarão mais concentradas [...]" (O Globo, 14/01, p. 3).

Diante da questão "o que deu errado na região serrana?" (FSP, 15/01, C6), a resposta diferentemente do ano de 1988, que estava mais concentrada nas atividades de gerenciamento da cidade, agora remete mais às falhas de dispositivos técnicos e científicos, à ausência de projetos e de profissionais especializados que se tivessem sido usados, ou melhor, usados preventivamente, os danos teriam sido menores, como verifica-se neste conjunto de enunciados:

"A história se repete, como se não houvesse previsão do tempo [...]" (FSP, 15/01, capa); "População não foi alertada na região serrana" (FSP, 15/01, C1); "Não há um plano integrado com o governo estadual e nem um sistema de alertas"; "falta de mapeamento de áreas de risco" (FSP, 20/01, C); "pouco investimento para prevenção como a apresentação de planos genéricos e incompletos" (FSP, 14/01, C5); "A previsão do tempo não é uma ciência exata, mas a falta de equipamentos e pessoal especializado, além de falhas de comunicação e do descaso das autoridades, pode ajudar a explicar a tragédia na Região Serrana" (O Globo, 18/01, p. 14).

A justificativa ressaltada para as medidas de prevenção, assim como em 1988, é a que privilegia o custo-benefício, pois a falta de investimentos, como inúmeras vezes apontado, traz prejuízos, "gastam muito mais para consertar estragos de desastres naturais do que com prevenção" (FSP, 14/01, C5). A projeção futura é a de que o sistema de prevenção deverá ser melhorado, já que o futuro é apresentado como mais sombrio e a urgência de medidas preventivas é ainda mais necessária: "a mudança climática, ao fazer com que tempestades se tornem mais comuns, deixa regiões serranas como a do Rio mais vulneráveis" (FSP, 13/01, C6); "a recorrência de eventos climáticos mais graves e mais frequentes lança o desafio premente da profissionalização do sistema nacional de defesa civil" (FSP, 16/01, B1).

Juntamente às propostas de remoção sempre presentes, "remoção em áreas de risco" (FSP, 25/01, capa), diferentemente de 1988, a discussão sobre a urbanização é atenuada pela demanda por intervenções locais por meio da instalação de sistemas e planos de alerta nas áreas de risco e treinamento de seus moradores. A vulnerabilidade pode ser atenuada por medidas que criam rotinas e hábitos para que a população possa antever as ameaças e adaptar-se a elas: "Rio instala sistema de alarme contra catástrofes [...] comunitários e sirenes para avisar à população [...] o cruzamento da previsão de mudança climática e dos dados geofísicos vai permitir a implantação do sistema de alerta" (O Globo, 18/01, p. 12); "pessoas especializadas e equipamentos adequados para as ações de prevenção" (FSP, 15/01, C1). 


\section{Considerações finais}

A história traçada por esta visão geral da pesquisa de ciências sociais sobre "desastres naturais" e o levantamento nos veículos impressos brasileiros de matérias sobre os "desastres naturais", especificamente os ocorridos com as chuvas de 1988 e 2011, buscaram mostrar que as catástrofes produzidas não são uma sequência natural e autoevidente, e sim uma problematização social e pública. Esta contribuição visa demonstrar a análise teórica e metodológica do discurso na mídia enquanto modo de estudar a construção das catástrofes como um objeto da ação pública.

Compreender como ocorrem os "desastres naturais" é colocá-los numa perspectiva social e histórica, pois são esses fatores que transformam um perigo em uma catástrofe. A vulnerabilidade social aos desastres não é só o resultado de um acontecimento presente, mas é igualmente e intimamente um produto do passado. Uma apreciação adequada da construção da vulnerabilidade é ainda muitas vezes dificultada pela falta de uma perspectiva a longo prazo para compreender os contextos e as raízes das causalidades dos desastres.

A questão que decorre atualmente - se as pessoas têm a capacidade de resistência para suportar os efeitos dos "desastres naturais", ou se são menos vulneráveis a eles através de projetos de adaptação por meio de treinamento, sistemas de alerta ou simulações de risco - faz com que, embora essas sejam ações importantes de prevenção, a questão da vulnerabilidade social seja duplamente elidida. Como foi argumentado, a partir da análise da cobertura jornalística impressa, há uma expressiva ausência da problematização da vulnerabilidade social nos dois momentos da pesquisa: ela não se faz presente nos discursos analisados, nem para apontar as desigualdades sociais e nem articulada à emergência dos "desastres naturais". Ao contrário, nas matérias de 2011, há mesmo o predomínio de medidas de preparação ou de ajustamentos em todos os níveis no sentido de adaptar as populações a "viver com o risco".

Conclui-se que os materiais em análise dão visibilidade a certa trajetória desses enunciados e que as ligações entre essas duas perspectivas, das ciências sociais e da mídia, são, sem dúvida, maiores do que o sugerido aqui. É importante destacar que conceitos, como vulnerabilidade, adaptação e resiliência, têm uma função performativa, pois orientam amplamente as políticas públicas. E, neste sentido, cabe perguntar se a trajetória identificada não estaria produzindo um cenário mais despolitizado e despotencializado, pois, ao invés de buscar identificar e remover as fontes da vulnerabilidade histórica e social associadas aos desastres naturais, passar-se-ia a conviver com ela como um fato ineliminável.

\section{Referências}

1. Aradau, C. (2014). Resilience: international policies, practices and discourses. In: Resilience, mai, p. 73-87.

2. Atlas de desastres naturais do Estado do Rio de Janeiro. (2013). Vol. 2 revisado. CEPED, UFSC, Florianópolis.

3. Banco Mundial. (2012). Avaliação de perdas e danos: inundações e deslizamentos na Região Serrana do Rio de Janeiro - Janeiro de 2011.

4. Bankoff, G. (2003). Cultures of disaster: society and natural hazards in the Philippines, Londres: Routledge, 2003. 
5. Bankoff, G. (2001). Rendering the wold unsafe: "vulnerability" as western discourse. Disasters, 25 (1): 19-35.

6. Becerra, S., Peltier A. (2011). De la crise environnementale à l'affirmation du concept de vulnérabilité: la construction progressive d'un champ scientifique interdisciplinaire In.: F. Rudolf. Sociologie de l'environnement: état des savoirs, Paris: L'Harmattan. Capítulo 5.

7. Blaikie, P., T. Cannon, I. Wisner, B. (1996). Vulnerabilidad. El entorno social, politico y económico de los desastres. In.: La RED. Disponível em http://www.desenredando.org/ Acesso: abril de 2015.

8. Brasil. (2014) Presidência da República. Secretaria de Comunicação Social. Pesquisa brasileira de mídia 2015: hábitos de consumo de mídia pela população brasileira. Brasília: Secom.

9. Brasil. (2012). Ministério da Integração Nacional. Secretaria Nacional de Defesa Civil. Centro Nacional de Gerenciamento de Riscos e Desastres.

10. Brasil. (2011). Anuário brasileiro de desastres naturais. Centro Nacional de Gerenciamento de Riscos e Desastres. Brasília: CENAD.

11. Bourg, D., Joly, P.B. et Kaufmann, A. (2014). Du risque à menace: penser la catastrophe. Paris: PUF.

12. Calhoun, C. (2013). The idea of emergency: humanitarian action and global (dis)order. In: FASSIN, D. E PANDOLFI, M. (Orgs.) Contemporary states of emergency. NY: Zone Books.

13. Gilbert, C. (2009). "La vulnérabilite! une notion vulnérable? À propos des risques naturels". In.: Becerra, S. \& Peltier, A. (dir.), Risques et environnement: recherches interdisciplinaires sur la vulnérabilitédes sociétés, Paris: L'Harmattan, p. 23-40

14. GonçAlves, R. S. (2015). "São as águas de março fechando o verão". In.: Acervo, Rio de Janeiro, V. 28, N. 1, Jan./Jun. p. 98-119.

15. Grove, K. (2014). "Biopolitics and adaptation: governing socio-ecological contingency through climate change and disaster studies". In: Geography compass. Volume 8, Issue 3, pages 198-210.

16. Hewitt, K. (1983). Interpretations of calamity: from the viewpoint of human ecology. Boston: Allen\&Unwin INC.

17. Foucault, M. (1984) “Le souci de verite”. In: Dits et écrits, tome 4 (1976-1988). Paris: Gallimard. p. 646-649

18. Foucault, M. (1995). A arqueologia do saber. Rio de Janeiro: Forense Universitária.

19. ISDR. (2002). Living with risk. A global review of disaster reduction initiatives. Geneva: United Nations.

20. Maia, A. C.N.; Sedrez, L. (2011). "Narrativas de um dilúvio carioca: memória e natureza na grande enchente de 1966”. História oral, v. 14, n. 2, p. 221-254.

21. Maskrey, A. (1993). Los desastres no son naturales, La RED. Disponível em http://www. desenredando.org/ public/libros/1993/Idnsn/LosDesastresNoSonNaturales-1.0.0.pdf

22. Lakoff, A. (2007). Preparing for the next emergency. In.: Public culture 19 (2), p. 247-271.

23. Lakoff, A., COLLIER, S.J. (2008). Biosecurity interventions. Global health and security in question. New York: Columbia University Press.

24. Pinheiro, M.A. (2015). “Catástrofes ambientais na mídia: narrativas das chuvas de 1966 e 2011 ”. In.: Revista mídia e cotidiano, 7. Niterói, PPGMC-UFF, Nov, p. 67-83

25. Quarantelli, E. L. (2002) "The Disaster Research Center (DRC) field studies of organized behavior in disasters”. In STALLINGS R.A. (Ed.), Methods of disasterresearch. Philadelphia: Xlibris, 94-116.

\section{4}


26. Revet, S. (2011). Penser et affronter les désastres: un panorama des recherches en sciences sociales et des politiques internationales, Critique internationale, 52, 3, 157-173.

27. Revet, S. (2010). Le sens du désastre. Les multiples interprétations d'une catastrophe "naturelle" au Venezuela. In: Terrain, n. 54, pp. 42-55.

28. Revet, S. (2007). Anthropologie d'une catastrophe. Les coulées de boue de 1999 au Venezuela. Paris: Presses Sorbonne Nouvelle.

29. Sendai. (2015). Framework for disaster risk reduction 2015-2030. United Nations Office for Disaster Risk Reduction (UNISDR). Disponível em http://www.unisdr.org/we/inform/publications/43291. Acesso: abril de 2015.

30. UNISDR (2009). Terminology on disaster risk reduction. Geneve: United Nations. Disponível em http://www. unisdr.org/files/7817_UNISDRTerminologyEnglish.pdf. Acesso: abril de 2015 